\title{
V-Lab: A virtual laboratory for teaching introductory concepts and methods of physical fitness and function
}

\author{
Mary Rice, David Owies, Adrienne Campbell, Rod Snow, \\ Neville Owen and Dale Holt \\ Deakin University
}

\section{Introduction}

The delivery of higher education courses is changing significantly with the rapid growth of new technologies which offer possibilities for learners that have previously not been available. In particular, the potential benefits of interactive multimedia (IMM) in educational environments have been well documented (see for example, Latchem et al, 1993; Laurillard, 1993; Halal and Liebowitz, 1994; Bates, 1995; Brookes, 1997; Reeves and Reeves, 1997). Web based interactive multimedia can provide many opportunities to enhance student learning and solve particular educational problems. Applications of this technology can increase the consistency, reliability and quality of what is delivered to students, and can provide immediate points of access to large bodies of relevant information through hypertext and selected links to related web sites. Furthermore, the technology allows students to work at their own pace and at a time of their choosing, thereby optimising conditions for learning and increasing the flexibility of the learning experience.

In this paper, we describe the development and evaluation of a "virtual laboratory" (V-Lab) for introductory practical studies of human structure and function in the movement sciences. Our purpose is to identify what we found to be some of the key elements of the development process for our first V-Lab and to introduce some of the technology used. Student and staff responses to its initial implementation are presented, based on a systematic evaluation using quantitative and qualitative methods. 


\section{Web based interactive multimedia in the human movement sciences}

In recent years, the use of multimedia in tertiary courses has become more widespread. This is evidenced by the growth in the number of national and international conference presentations, journal articles and listserv discussions focusing on multimedia developments in a variety of discipline areas. (See for example, AACE, ASCILITE, ED-MEDIA and WebNet proceedings, AJET, BJET, JILR, JEMH and WebNet journals, AAHESGIT, ED-TECH, and ONLINE-ED listservs)[1]. Some of these developments relate to the use of multimedia in the broad area of health sciences. For example, Zelmer (1995) discussed the use of interactive multimedia to teach students how to care for individuals with diabetes. Another program was designed to assist occupational therapy students make case management decisions (Cameron, 1996 cited by Alexander and McKenzie, 1998), while Medici was developed to provide case based simulation to supplement ward based teaching (Devitt and Palmer 1995). A number of other, similar examples are cited in the literature.

However, there have been fewer developments relating specifically to human movement. Projects undertaken in Australia in the last few years include the Sarcomotion project, described by Fyfe, Fyfe and Phillips (1995) as an IMM tutorial using animations and background information to assist students' understanding of the microscopic process of skeletal muscle contraction. Browne and Ellis (1997) describe a project which uses IMM to present seven morphometry practical exercises previously presented in paper format, while Olds and Norton (1997) created a CDROM containing a virtual testing environment that simulates a range of physiological tests for students studying exercise science. The Motion Toolbox described by Kirtley and Smith (1997) was developed to facilitate students' study of motion by linking abstract concepts with real muscle movement. Kirtley and Smith (1997) note that the human movement sciences are not well suited to didactic, traditional approaches that use static images on printed pages. Rather, as has been demonstrated by developments mentioned above, and as will be evident from this paper, the use of multimedia lends itself very well to the teaching of human movement concepts.

Most of the developments outlined above have produced stand alone multimedia programs with some providing links to web based resources. $\mathrm{V}$-Lab has added functionality through the web based dynamic database connectivity. 


\section{Theoretical considerations}

In the early years of undergraduate learning, students studying human movement often require hands on laboratory experiences that engage them in active learning. They deal with aspects of human structure and function where highly visual, interactive learning media can be used to considerable advantage and can supplement and, at times, substitute for hands on learning experiences (Olds and Norton, 1997). Through the use of concepts and techniques from the now well established body of knowledge on multimedia based learning (for example, Jonassen and Reeves, 1996; Schwier and Misanchuk, 1993), there is the potential to develop some unique methods to enhance student learning around key aspects of human structure and function. In particular, teaching human movement students through a web based multimedia environment can enable the use of highly credible simulations of hands on laboratory experiences. This can involve learning about specific equipment, about testing procedures for assessing a number of aspects of physical function and fitness and can guide students through strongly grounded experiences in data gathering, data entry, data analysis, interpretation and applications. In many ways, the laboratory learning requirements for basic human movement studies relating to physical function and assessment can, if translated appropriately into a multimedia learning environment, meet many of the criteria for "situated learning" described by Herrington and Oliver, (1997). According to Herrington et al (1997, p.269),

Situated learning places learning in the context in which it will be later applied. One of the principal effects claimed for the theory of situated learning is that it facilitates transfer of learning to new situations.

$\mathrm{V}$-Lab is designed to provide initial experiences within a 'virtual laboratory' so that the knowledge can be transferred more readily to real laboratory situations. In particular, the program adheres to the first two critical guidelines cited by Herrington and Oliver, (1997, p. 128). It has 'a physical environment reflecting the way the knowledge will ultimately be used', and 'a non-linear design to preserve the complexity of the real-life setting'. Being web based, it also has links to other resources. V-Lab is one element of an integrated package of learning experiences, which in totality provides 'a large number of resources to enable sustained examination from a number of different perspectives'. (Herrington and Oliver, 1997, p. 128) 
It can reasonably be assumed that a multimedia based situated learning environment that simulates a real life experience is one that will strongly encourage active learning. However, multimedia of itself does not promote active learning, it is the strategies and activities that are incorporated into the medium that are the critical elements. As Brooks (1997) notes, 'interactivity has become the really critical design issue. Interactivity implies that active learning will be encouraged'.

Meyers and Jones (1993, p.19) contend there is 'no generally agreed upon definition of active learning'. It is often defined as something that contrasts to traditional didactic approaches where students are passive recipients of information. In other words, it is more often defined in terms of what it is not. Nonetheless, Brookes (1997, p. 14) argues that where curriculum resources 'force students to respond, to make choices, to perform, to organise, to think deeply about the material', active rather than passive learning is generally the outcome. Active learning is generally regarded as student centred rather than teacher centred: it demands active participation on the part of the learner, participation beyond the level of a point and click activity.

\section{Background and rationale for the V-Lab project}

Early in 1997, the School of Human Movement at Deakin University received University funding to develop key first year units in off campus / flexible delivery mode with a strong emphasis on the use of unit web sites and technology mediated learning enhancements. A School based "Web Working Group" was established and the School's Academic Services Manager was appointed to coordinate the development of flexible learning materials including online, print, and audiovisual resources. Other staff with expertise in software development and HTML editing were also appointed. In addition, the School invested considerable funding in purchasing the most up to date computer hardware and software for its staff and a dedicated NT server to enable data storage and processing.

To facilitate development of resources, discussions ensued between relevant school based staff, the Deakin Centre for Academic Development, and Learning Resources Services. The initial discussions focused on a re-assessment of the content of the School's main level one unit. This included considerations of past student satisfaction with the unit, student numbers, access to equipment, time constraints on lecturers 
and tutors, financial restraints, availability of content experts, and the level of enthusiasm for ongoing implementation of flexible teaching and learning. All areas of the unit were examined to ascertain how technology could enhance the teaching and learning experience for lecturers and students. It was noted that the Physiology Laboratory component of the unit was suffering because large numbers of students were trying to work in overcrowded laboratories. This resulted in students having insufficient hands on experience with the equipment. There was also the problem of trying to teach complex fitness testing procedures and data processing within relatively short time frames.

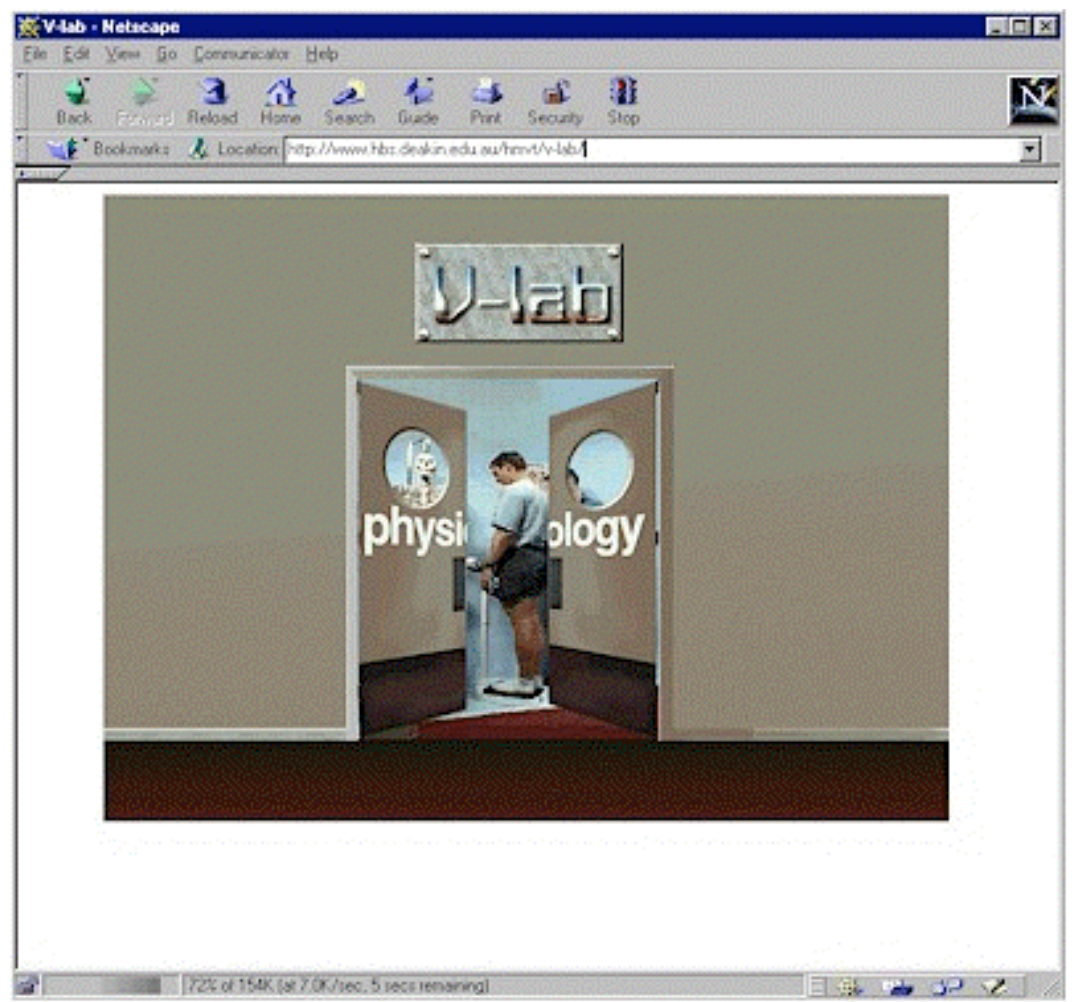

Figure 1: The Virtual Laboratory (V-Lab) homepage incorporating the use of Quicktime VR Movie technology.

To address these concerns the decision was made to deliver this procedural content on the WWW as both a pre- and post-laboratory experience. This led to the development of a Virtual Laboratory (V- 
Lab)[2]. As the web environment had already been chosen to deliver much of the unit content, it became clear that this mode of delivery would be appropriate for the school and the specific needs of the particular units. The viability of the V-Lab concept was considered to be sound, as the VLab template could be utilised within other units, ultimately saving time and money.

\section{The development of V-Lab}

The objectives of developing V-Lab were to:

- Provide a virtual laboratory in which students' could work to reduce the need for them to work in overcrowded campus laboratories.

- Enhance the learning process for students studying the series of health related laboratory tests in the unit Physical Activity, Fitness and Health, by providing opportunities for them to carry out fitness testing in a virtual environment.

- Enable students studying Human Movement to engage with information technology, especially WWW based software.

- Encourage students to utilise the unit web site resources and the more general computer based resources available on campus.

- Alert academic staff to the availability of WWW based technologies and encourage them to make sound educational use of them.

\section{Software and hardware used}

A combination of both HTML pages and Macromedia Director applications delivered via Shockwave technology were used to develop V-Lab. QuickTime Virtual Reality (VR) Movie was also used to enable 360 degree visual exploration of the laboratory equipment. HTML templates were produced for the substantive content of V-Lab and Macromedia Director applications were developed to perform the fitness testing calculations. A Microsoft Access database was utilised to store and retrieve student submitted results. The database enabled students to submit results and return at a later date to retrieve these results and continue working within the Macromedia Director application.

V-Lab was developed as an online laboratory that could be accessed via the School of Human Movement website. It is an interactive program that provides opportunities for students to carry out fitness testing online in each of the following areas: Anthropometry, Muscular Strength, Aerobic 
Power, Anaerobic Power, Lung Function, and Flexibility. For each fitness component, there are four sections through which students work:

Introduction provides background information about the particular fitness area and the nature of the test.

Equipment describes the equipment used to conduct the test and provides photographs of each piece of equipment.

Procedure outlines instructions on how to conduct the fitness test and includes photographs and/or video clips to demonstrate each step.

Data processing contains a calculator icon which enables students to calculate and save results, then submit them to the database.

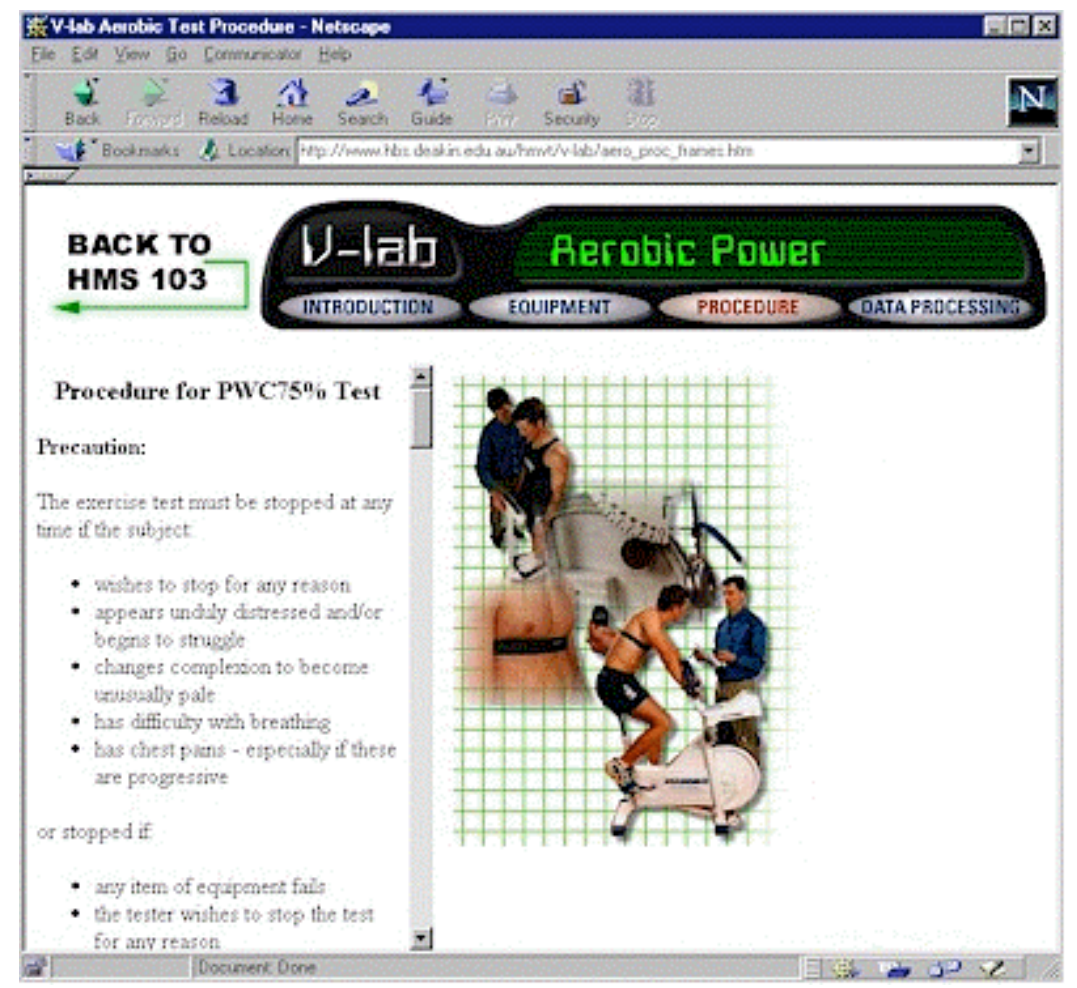

Figure 2: Outlines instructions on how to conduct the aerobic fitness test and includes photographs and/or video clips to demonstrate each step. 


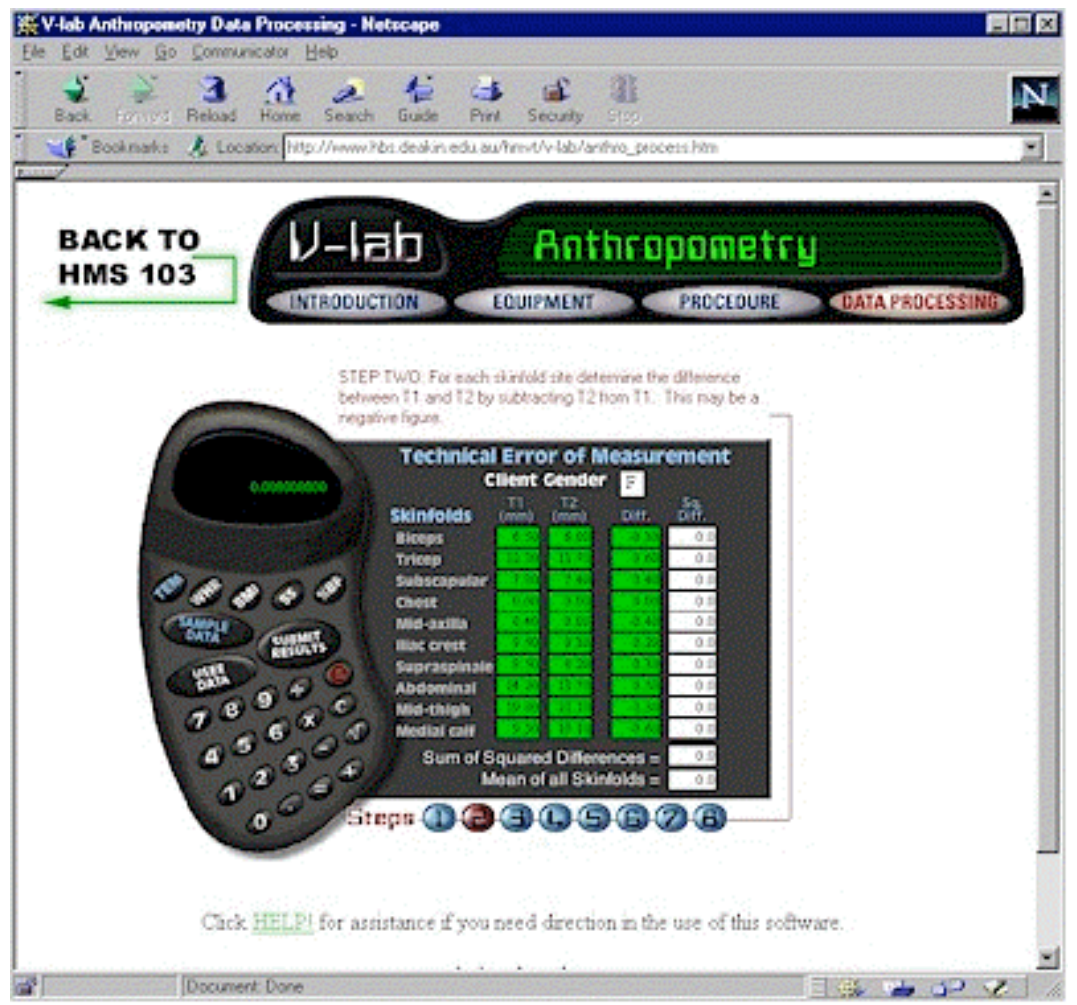

Figure 3: V-Lab Data Processing html page showing interactive (Macromedia Director) process for calculating Technical Error of Measurement in the Anthropometry section.

\section{Evaluation objectives and methods}

The main focus of the evaluation was on the initial use of V-Lab in the level one unit "Physical Activity Fitness and Health". The objectives of this pilot evaluation were to document:

- aspects of the development process

- students' general experiences in using V-Lab

- students' beliefs about the educational value of V-Lab

- the main technical, access and educational problems associated with using the software

- staff perceptions about the value of the software and the implementation process 
Evaluation methods used at different stages of the implementation process were as follows:

- Three focus group sessions were held with students during the semester when V-Lab was introduced. Eight students attended the first session, and three attended the remaining two sessions. Students were paid volunteers.

- An online questionnaire was included in the V-Lab web site and responses were received from 203 of the 306 students enrolled in the unit. FrontPage was the application used to develop the questionnaire because it enabled drop down boxes to be used for response choices (the URL for this questionnaire is http:/ / www3.deakin.edu.au/hmvt).

- Telephone interviews were conducted with two of the lecturing staff and three tutors. Note taking was used to record the main ideas. Other teaching staff were contacted by email and invited to provide feedback about V-Lab.

- Data were gathered from the Project Manager and software developer via email and during informal discussions.

\section{Limitations of the evaluation}

Being a pilot, the evaluation was clearly limited in the extent to which it could assess the impact of V-Lab on students' learning styles and outcomes. When implementing new technologies, there are many factors that warrant evaluation. Decisions had to be made about particular foci at particular stages of the development and implementation processes. At the pilot stage, it would have been premature to attempt to assess the impact of V-Lab on student learning. Indeed, at any stage it is difficult to examine the real impact of technology in isolation from other variables.

In reporting the data, percentages are used to provide some indication of users' perceptions. It is recognised that more detailed data about students' engagement with the program will be need to be gathered in the future. Nonetheless, as Scanlon and colleagues (1997) point out, students' perceptions are important in determining whether they are likely to repeat an experience such as using a web based learning environment. If V-Lab is going to be accepted as an integral part of their curriculum, students must perceive it to be of value. 


\section{Findings of the evaluation of V-Lab}

\section{General issues}

All 306 students studying the unit "Physical Activity, Fitness and Health" used V-Lab and $66 \%$ of them responded to the questionnaire. They were all enrolled at one campus and $98 \%$ of them studied in on campus mode. The majority of the students were female $(71 \%)$, aged between 17 and 19 years $(86 \%)$, most had studied Physical Education at VCE level $(78 \%)$ and believed they were sufficiently experienced to enable them to use V-Lab quite comfortably. It should be noted that $25 \%$ of students were inexperienced and this equates roughly with the number who did not enjoy using computers $(24 \%)$. While the inexperienced people are not necessarily the same group as those who do not enjoy computers, it is likely there was some overlap.

Most students accessed the software on computers in the campus laboratories, although $12 \%$ successfully accessed it from home or from another remote site. The majority of students $(74 \%)$ found the software easy to use after attending the familiarisation session, and over $75 \%$ found the written instructions helpful. Students with less computer experience would have liked instructions written in simpler language; they found it difficult to understand some of the computer terms used.

$\mathrm{V}$-Lab was seen as being only a small component of the overall unit, albeit an important one. The majority of students $(81 \%)$ spent between 1 and 5 hours using the V-Lab program, with a further $12 \%$ using it for 5 to 10 hours. This is consistent with the expectation that most students would complete the required work in 4 to 6 hours, but represents a relatively small proportion of the time needed for study in the unit overall. If technology is to make a difference to students' learning outcomes, it needs to be central to the course and an important aspect of learning in most units (Bates, 1995). This points to the need to further develop the VLab technology and to do so in conjunction with a comprehensive staff development program. As Laurillard (1993) points out, working with technology requires a significant culture change on the part of teachers and students.

\section{Perceptions about educational value}

Most students believed that V-Lab was a beneficial educational tool. Almost half of them (49\%) rated it highly and a further $41 \%$ believed it to be of medium value. This suggests that they have accepted it as part of the curriculum and are likely to use such programs again (Scanlon et al 
(1997). More than four-fifths of the students clearly understood the purpose for using V-Lab and believed the concepts were presented in comprehensible language which made them easy to understand. Focus group discussions revealed that while students expected to be using computers in their courses, they thought it would be mainly for word processing. They did not expect 'something as impressive as V-Lab' and believed it made Deakin's course more appealing by providing an alternative, more interesting mode of learning.

Approximately three-quarters of the students agreed that the interactive features of V-Lab (such as the data processing and database functions) made the topic more interesting, while just over half $(56 \%)$ thought the electronic medium enhanced their enjoyment of learning.

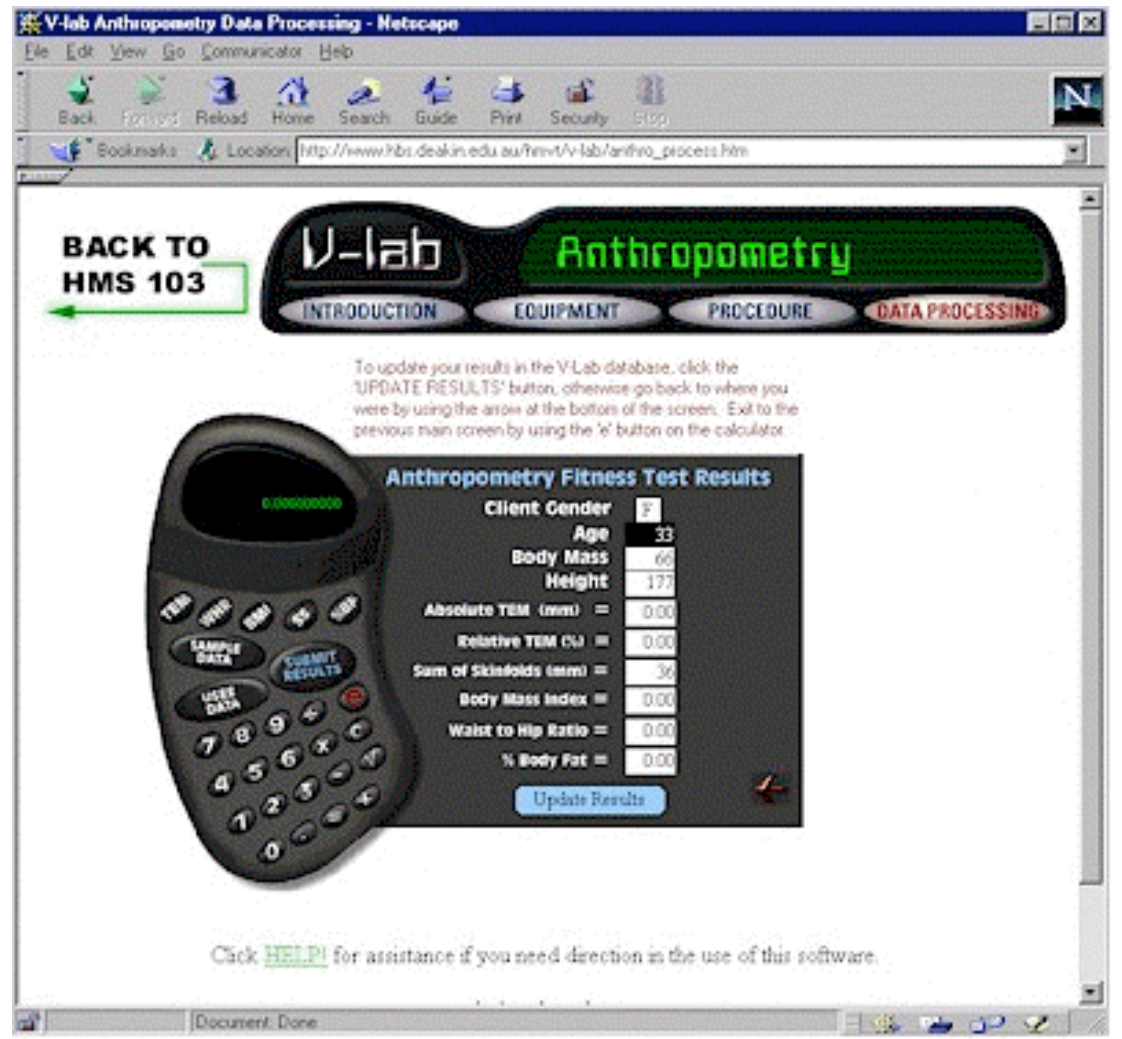

Figure 4: Macromedia Director interface for student results submission to the database. 
Most students (79\%) believed that the photographs in V-Lab helped their learning and the content was pitched at an appropriate level, though a few thought it assumed too much knowledge. In particular, focus group students mentioned the value of the photos of different skinfold sites. Generally, students thought the V-Lab web site compared favourably with other web sites.

In respect to students' perceptions, the above findings are consistent with results from similar studies outlined previously. (Fyfe, Fyfe and Phillips, 1995; Kirtley and Smith, 1997; Olds and Norton, 1997). Students are clearly responsive to the visual and interactive elements of IMM.

Of the 150 students who provided qualitative comments, $75 \%$ were positive. Many were brief summative remarks such as:

- Extremely useful and very, very impressive.

- Pretty good as it is fairly easy to use and learn from.

A number of comments from questionnaires and focus groups highlighted the value of V-Lab as an alternative medium for learning and one which allowed students to work at their own pace and in their own time. Typical comments along these lines included:

- People learn in different ways and it's good to have variety.

- I think it is an effective way to educate students, as it maintains interest and is a different way of learning.

- Writing tables by hand is confusing and boring. V-Lab makes it easier and more interesting and I like the fact that we don't have to spend ages doing pen and paper calculations for fitness testing.

These comments suggest that students appreciated a variety of media for learning and in particular, they like programs that reduce the tedium of pen and paper calculations. Browne and Ellis (1997) also cite students' satisfaction with a multimedia program that reduces reliance on pen and paper work.

Four-fifths of the students believed that, as a result of using V-Lab, they understood more clearly how to carry out fitness testing for each of the six fitness components. Similarly, three-quarters of the students believed that V-Lab helped them to better understand how to calculate the appropriate data for each of the fitness components. Typical comments from students included:

- It allowed me to gain a better understanding of the techniques involved in performing the tests successfully and also I now have greater knowledge on how to calculate the results for each test. 
- It helped me to better understand the reasoning behind the testing and how to do the tests. It is easier to remember the processes if you see them happening in front of you.

- (V-Lab) makes you think about the figures you are entering in and the procedure that you use to obtain your results.

- The data processing section reinforced learning and was a practical, hands on part of the program which helped people learn through experience.

While these comments are perceptions only, they provide some support for the notion that V-Lab encourages active learning in a situated environment. In the virtual laboratory, students have engaged in those activities that Brooks (1997) regards as being consistent with active learning. They have responded, made choices, performed tests, organised findings and thought more deeply about the material. However, this needs further corroboration through research that more closely observes students' patterns of behaviour and provides a more detailed analysis of outcomes.

\section{Technical issues}

Some $9 \%$ of comments reflected dissatisfaction with V-Lab. These comments related to the problems associated with the software and also revealed some negative attitudes towards the use of computers.

- I do not think it is necessary to use computer stuff for a lot of things.

- V-Lab was at times frustrating, especially to those with no previous computer experience.

These students would find support from Stoll (1995) who argues that computers can generate much frustration for learners and can sometimes be less efficient than more traditional modes of learning.

When students are expected to use new technology in their courses, it is common for a number of them to experience access problems. V-Lab was no exception: $26 \%$ found it difficult to access computers in campus laboratories. Data from university surveys have indicated that most students try to access the laboratories between $11 \mathrm{am}$ and $3 \mathrm{pm}$. Students who try early in the morning or later in the day generally have no problems. While the data are not specific to students using V-Lab, it is possible that they followed the access patterns found elsewhere.

As the data indicate, students' initial perceptions of V-Lab were positive. This suggests strongly that they were accepting of the software and will be likely to use it again. (Scanlon et al 1997) 


\section{Academic staff perspectives}

Academics were generally positive about the development of V-Lab, although some had very little involvement with it in the early stages. Staff who were most directly involved were very pleased with the outcome and with the students' reactions to the software. It is evident that students' positive attitudes and their general acceptance of the technology have strengthened the level of staff interest in further V-Lab development.

Because tutors interacted with students on an individual basis, they were more familiar with V-Lab than were most of the lecturers. They were very supportive of it and were well prepared for its implementation. Tutors were aware that when implementing technology, some problems inevitably arise, so they were less frustrated when certain aspects of the calculator didn't work and the data processing could not be completed. They prepared students for such eventualities by having them work out their calculations and write down results in case they could not process them. Tutors found that some students did not thoroughly read the information in their notebooks and did not read all the instructions in the laboratories; they relied too much on tutors telling them what they had to do. Furthermore, the lack of computer experience of some students meant that they required much more support from tutors than would normally be the case. Laurillard (1993) argues that academic staff have to be aware of the integrative task required when implementing new technology and need to provide additional support. This was clearly forthcoming in respect to V-Lab.

Overall, tutors believed V-Lab to be an excellent resource for students who are self motivated. Less interested students tended to move through the lab work quite quickly and did not do as much preparation work. As a result, they probably did not engage fully in the active learning strategies and therefore did not receive the full benefits of the program.

\section{Factors affecting implementation}

To some extent, implementation and integration of V-Lab benefited from the findings of evaluations of other technologies at Deakin. There were a number of factors that clearly facilitated these processes, including:

- The level of leadership, support and commitment to the project from the Head of School and other key Human Movement staff.

- The initial laboratory session run by the Project Manager and Multimedia Programmer to prepare tutors for the implementation. 
- Plans for ensuring that there were enough computers available for students in campus laboratories.

- The familiarisation sessions run for students and a 24 hour mobile ‘help line' available for support purposes.

- The contingency plans put in place to reduce students' anxiety about submitting results and minimise disruption to their studies.

While the implementation was successful as a result of the above mentioned factors, there were some problems that constrained the process. These were the:

- Limited time available for tutors to familiarise themselves thoroughly with the software because of the rushed completion of the database connectivity aspects.

- A technical bug which frustrated students because it prevented them from saving and submitting data on some occasions.

- Delayed installation by the University's Information Technology Services Division of the Shockwave plugin and associated problems with computers freezing when attempts were made to load the Shockwave facility.

\section{Discussion and conclusion}

It is difficult to attribute particular learning outcomes to specific learning events such as V-Lab because so many other variables impact on the learning process. Nonetheless, it is clear that most students believed that VLab had positively affected the extent of their learning. The findings suggest that the program was slightly more successful in helping students to carry out fitness testing than in helping them learn to calculate the appropriate data. However, further research is needed to determine more fully the educational benefits of V-Lab and the extent to which it enhances students' learning and produces improved learning outcomes. When reviewing numerous technology based projects, Alexander and McKenzie (1998) highlighted the need for more rigorous research that produces data beyond the stage of initial user perceptions. Cavelleri (1998) also notes that "lots of independent research" is needed to assess the effectiveness of multimedia for student learning.

For most students, the objectives of developing V-Lab appear to have been achieved. In particular, the use of V-Lab has helped to reduce the amount of time that students spend in the actual laboratories and has ensured that they are better prepared for their real laboratory work. It has also ensured that students and staff use online technology as part of the teaching and learning experience. Nonetheless, it appears that both 
students and staff could make more use of the web site and its resources as a means of improving learning outcomes. This change in work culture may be achieved gradually through a series of staff development sessions and particularly when more V-Labs are developed. Harasim et al (1995) highlight the need to provide training, support and encouragement before and during implementation of online learning environments.

The development of V-Lab has increased flexibility for students who, within the parameters of unit requirements, can complete the work in their own time and at their own pace. The small percentage of students who successfully accessed V-Lab at home enjoyed even greater flexibility. As more students begin to do this, the advantages will become more evident.

Being a pilot implementation, some technical problems were to be expected, but contingency plans and strong technical and educational support helped to minimise the fall out from the few problems that did occur. Staff and students were well prepared for the new technology implementation. They did not panic when problems arose and consequently, most students were not distressed by the problems. By ensuring that staff and students had some understanding of the nature of technology development and implementation, levels of frustration were minimised as far as possible. The Human Movement program at Deakin University has now established a strong basis on which to proceed with further development of the web site and online laboratories, a move that would appear to have the strong support of the student cohort.

The student, staff and laboratory tutor feedback that we obtained presents $\mathrm{V}$-Lab in a positive light. Our routine quality assurance reports, ongoing assessments and final examination data show no evidence of decrements in student learning associated with the significant reductions in hands-on laboratory time associated with our use of V-Lab.

As is the case for many educational innovations, we have identified significant ethical and practical difficulties in designing ways to carry out systematic concurrent comparisons of our traditional laboratory teaching versus V-Lab. Ideally, matching or randomly allocating students to these two forms of delivery and comparing outcomes would allow a more rigorous evaluation to be carried out. Another option might be to compare a more basic form of V-Lab delivery with the full, interactive version. In either case, putting aside ethical considerations, the practical difficulties remain formidable, particularly those associated with inevitable communication between students in the two different programs. 
Our strategy for future V-Lab evaluations will be to track student experiences and ratings of the V-Lab program, using brief online survey forms to be completed by all students at the end of several V-Lab sessions throughout the unit. Student perceptions of key dimensions (for example, interactivity, satisfaction simplicity of use) and assessments of meeting learning objectives will be included.

Careful, detailed, critical analysis of key elements of student learning through continuous assessment seems to us to be the most productive evaluation strategy, one where the technology itself can be used to good effect (particularly using online survey forms linked to a database). It seems to us that the uses we have made of information technology and interactive multimedia capacities in V-Lab certainly creates efficiencies in delivery of unit material and probably does enhance student learning and motivation. However, meticulous ongoing assessment and the careful interpretation of quantitative and qualitative data will be required before we can be more confident that these new learning enhancement methods achieve what we hope they do.

Flexible delivery of programs is a priority for Deakin University as a whole. This includes the appropriate use of web based interactive multimedia to enhance student learning. For both off campus and on campus students, screen based literacy and numeracy plus skills and confidence in using interactive multimedia are important educational objectives. Today's students will pursue their future careers in a society where information technology capacities evolve ever more rapidly and new applications will proliferate (Broderick, 1998; Tuckle, 1997). The ability of students not only to use this technology but to appreciate its potential and creatively exploit it as an integral part of lifelong learning, can be potentially significantly enhanced through learning experiences like those we have described.

\section{Endnotes}

1. List of acronyms

AACE - Association for the Advancement of Computers in Education

ASCILITE - Australasian Society for Computers in Learning in Tertiary Education

ED-MEDIA - Educational Media

AJET - Australian Journal of Educational Technology

BJET - British Journal of Educational Technology

JILR - Journal of Interactive Learning Research

JEMH - Journal of Educational Multimedia and Hypermedia

AAHESGIT - American Association for Higher Education Special Group on Information Technology 
ED-TECH - Educational Technology

2. The URL for V-Lab is :

http: / / www.hbs.deakin.edu.au/hmvt/v-lab/default.htm

\section{References}

Alexander, S. \& McKenzie, J. (1998). An evaluation of information technology projects for university learning. Committee for University Teaching and Staff Development. Commonwealth of Australia.

Bates, A.W. (1995). Computer based learning and multimedia. In Bates, A. Technology, open learning and distance education, (pp. 180-201). Routledge, London.

Broderick, D. (1997). The Spike. Kew, Australia: Reed Books.

Brooks, D.W. (1997). Web-teaching: A guide to designing interactive teaching for the World Wide Web. Plenum Press: New York.

Browne, C. \& Ellis, A. (1997). Putting it all together: Issues relating to the completion of a large student-produces multimedia project. In R. Kevill, R. Oliver \& R. Phillips, What works and why. ASCILITE '97 Conference Proceedings, 7th -10th Dec., Curtain University of Technology, pp. 82-87.

Cavelleri, B. (1998). Educational multimedia: Breaking records or breaking even. In Corderoy, R. (ed), Flexibility: The next wave. ASCILITE '98 Conference Proceedings, 14th-16th Dec., University of Wollongong, pp. 23-28.

Devitt, P. \& Palmer, E. (1995). Application of a problem-oriented learning package in medical education. In J. Pearce and A. Ellis, Learning with technology. ASCILITE '98 Conference Proceedings, 4th-6th Dec., The University of Melbourne,

Fyfe, G. Fyfe, S. \& Phillips, R. (1995). Sarcomotion: IMM used across the learning spectrum. In J. Pearce and A. Ellis, Learning with technology. ASCILITE '95 Conference Proceedings, 4th-6th Dec., The University of Melbourne, 186-195.

Halal, W.E. \& Liebowitz, J. (1994). Telelearning: The multimedia revolution in education. Futurist, Nov/Dec 94, 28 (6), 21.

Harasim, L. Hiltz, S.R., Teles, L. \& Turoff, M. (1995). Learning Networks: A field guide to teaching and learning online. Massachusetts, Massachusetts Institute of Technology Press.

Herrington, J., \& Oliver, R. (1997). Multimedia, magic and the way students respond to a situated learning environment. Australian Journal of Educational Technology, 13(2), 127-143.

http: / / www.ascilite.org.au/ajet/ajet13/herrington.html

Herrington, J., Oliver, R., Herrington, T. \& Sparrow, L. (1997). Enhancing transfer from interactive multimedia to real world practice. In R. Kevill, R. Oliver \& R. Phillips (Eds.), What works and why, ASCILITE '97 Conference Proceedings (pp. 269-275). Curtain University of Technology, Perth. 
Jonassen, D.H., \& Reeves, T.C. (1996). Learning with technology: Using computers as cognitive tools. In D.H. Jonassen (Ed.), Handbook of research on educational communications and technology (pp.693-719). New York: Macmillan.

Kirtley, C. \& Smith, R. (1997). Application of multimedia to the study of human movement. In R. Kevill, R. Oliver \&R. Phillips (Eds.), What works and why, ASCILITE '97 Conference Proceedings (pp. 338-341). Curtain University of Technology, Perth.

Latchem, C., Williamson J. \& Henderson-Lancett, L. (1993). (Eds.) Interactive multimedia. Kogan Page, London.

Laurillard, D. (1993). Rethinking university teaching: A framework for the effective use of educational technology. Routledge, London.

Meyers, C. \& Jones, T.B. (1993). Promoting active learning: Strategies for the college classroom. San Francisco: Jossey-Bass.

Olds, T.S., \& Norton, K.I. (1997). Virtual Machines (CD-ROM and manual). Adelaide: University of South Australia.

Reeves, T.C. and Reeves, P.M. (1997). Effective dimensions of interactive learning on the WWW. In Khan, B. (Ed.) Web-based instruction, Englewood Cliffs, NJ: Educational Technology Publications.

Scanlon, E., Tosunoglu, C., Jones, A., Butcher, P., Ross, S., Greenberg, J., Taylor, J., \& Murphy, P. (1997). Learning with computers: Experiences of evaluation. Computers and Education 30(1/2), 9-14.

Schwier, R.A. \& Misanchuk, E.R. (1993). Interactive multimedia instruction Englewood Cliffs, NJ: Educational Technology Publications.

Stoll, C. (1995). Silicon snake oil: Second thoughts on the information highway. New York: Anchor.

Turkle, S. (1995). Life on the screen: Identity in the age of the internet. New York: Simon \& Schuster.

Zelmer, L. (1995). Re-examining the myth: Developing truly affordable multimedia. In J. Pearce and A. Ellis, Learning with technology. ASCILITE '95 Conference Proceedings, 4th-6th Dec., The University of Melbourne.

Mary Rice[1], David Owies[2], Adrienne Campbell[1], Rod Snow[2], Neville Owen[2] and Dale Holt[1]

1 Deakin University, Centre for Academic Development 2 Deakin University, School of Health Sciences

Correspondence: Mary Rice, Centre for Academic Development, Deakin University, 1 Gheringhap Street, Geelong Victoria 3217

mrice@deakin.edu.au 